\title{
Willingness to Join and Pay Social Health Insurance and Associated Factors Among Public Sectors Workers in Didu Woreda, South West Ethiopia, 2018
}

Zelalem Regassa ( $\sim$ zrbilisumma78@gmail.com )

Fred Hollows Foundation at East Wollega Zone

\section{Ebissa Negera}

Mettu University

Tesfaye Silashi

Mettu University

Zalalem Kaba

East Wollega Zonal Health Department

\section{Research Article}

Keywords: Social Health Insurance, Willingness to pay, Willingness to join, Didu Woreda, Public sectors.

Posted Date: March 9th, 2022

DOI: https://doi.org/10.21203/rs.3.rs-1362030/v2

License: (c) (i) This work is licensed under a Creative Commons Attribution 4.0 International License. Read Full License 


\section{Abstract}

\section{Background}

Social health insurance is a form of healthcare financing mechanism for raising and pooling funds to finance and manage health services to attain universal health coverage. Cost-sharing between beneficiaries and governments is critical to achieving universal health care coverage. To address this, Ethiopia is currently introducing social health insurance.

Objective

To assess the willingness and associated factors to join and pay social health insurance among public sectors workers in Didu woreda, southwest Ethiopia,2018

Methodology

A cross-sectional study was conducted from April 15-30, 2018 on 280 public sector workers of Didu Woreda. Stratified and simple random sampling techniques were used, and data were collected using a structured interviewer-administered questionnaire. Binary logistic regression analysis was used to compute crude odd ratio with its $95 \%$ confidence interval to test the associations between dependent and independent variables and a P-value of 0.05 with a confidence interval of $95 \%$ was used to declare the level of statistical significance.

Results

280 public sectors workers participated, with a response rate of $98.2 \%$. About $33.6 \%$ of the public servants had never heard of any type of health insurance scheme. However, $47.5 \%$ of them were willing to join for the suggested insurance scheme from these about $58 \%$ of those who were willing to join are willing to pay $3 \%$ of their monthly salary that was proposed. Willingness to join was significantly associated with the age of respondents, marital status, job description, how much paid, the satisfaction of the respondents, and previous history of borrowing money for the medical service fees.

Conclusion

willingness to join and pay in this study was found to be $47.5 \%$ and $58 \%$ respectively. Therefore, adequate awareness creation and discussion should be made with all employees.

\section{Background}

A fundamental feature of achieving universal coverage is to develop a financial risk pooling system that provides cross-subsidies in health systems where the ability to pay determines, financing contributions, and the use of services is based on the need for care. The enjoyment of the highest attainable standard 
of health is one of the fundamental rights of every human being. These rights are exercised without distinction of race, religion, political belief, and economic or social condition [1-2].

All WHO member states are committed to achieving universal health coverage. The states had a central focus and belief of providing access to healthcare services to their people without risk of financial ruin or impoverishment. All of them had an ideology of, thus, achieving better health and well-being is a key for promoting human and economic development. Universal health coverage is an aspiration to reach the highest attainable standard of health. Alma-Ata Declaration which states "health for all" is best known for promoting primary health care as a means to address the main health problems in communities like fostering equitable access to primitive, preventive, curative, palliative, and rehabilitative healthcare services to the society is an icon [2-4].

The World Health Report on health systems financing proposes that countries of all nations at all income levels should constantly seek to modify and adapt health systems financing to the specific goal of universal health coverage. The report had the twin goals of ensuring access to health services and financial risk protection towards achieving sustainable development [5-6].

Social health insurance was first introduced to the world in Germany in the year 1883. Under the pioneering leadership of Chancellor Bismarck. Germany established the first system of compulsory Sickness insurance. The first Social health insurance scheme had the aim of providing independent occupation-based sick funds, but placing their activities under the state's sponsorship. The system was operational through mainly five ways, these were: - relief funds for journeymen, for craftsmen, factory workers, for workers or tradespeople (community), and relief funds for people who could not otherwise find insurance. The proposed insurance system had a goal of helping and securing workers [7].

The social health insurance scheme covers formal payroll-based employees and has distinct characteristics. The scheme has a compulsory mechanism that members have to pay the specified premium (contribution) periodically. While the government may decide to pay the premium on their behalf. Citizens only become entitled to these benefits when they have paid the required premium regularly. The premiums and benefits are described in a social compact, usually expressed in legislation. Social health insurance is different from user fees or direct payment schemes. In Social health Insurance, the user only is responsible for the payment of his or her medical treatment. The scheme shares it's characteristic of pooling of risks and contributions with health financing via regular general taxation [810].

New health sector financing reform (HSFR), initiatives with a growing international consensus towards social protection via strong health care financing, the Ethiopian Government under Proclamation No. 690/2010 established the Ethiopian Health Insurance Agency(EHIA). In June 2011 the agency launched a pilot Community-Based Health Insurance scheme. It was based on directives provided by the Federal Ministry of Health (FMOH). EHIA acquired an objective that any beneficiary of the social health insurance scheme shall have the right to receive the different health services from health service providers that 
contracted with the agency. The main benefit of the scheme is reducing the need to borrow money, which may have longer-term benefits in reducing the vulnerability of insured's to other forms of shocks [11-13].

In the world, particularly in developing countries, many people are suffering and dying due to a lack of access to even the most basic medical care. This is due to the inability of the poor and unexpected health shock, to pay for health care services. According to the study, a survey that covers about $89 \%$ of the world's population suggests that 150 million people suffer financial catastrophe every year due to out-ofpocket health expenditures. Furthermore, other important issues in low-income countries are that there is spiral poverty (vicious circle) which is due to the inability to work more because of poor health regardless of such health expenditure. Although limited governments' budgets for health care are a serious problem in many developing countries, there is a mechanism to provide low-cost health insurance to low-income households which are an innovative method through which to reach health care providers and decrease out-of-pocket health expenditures [14-15].

In many developing countries, the lack of adequate health care budget is a severe problem. Innovative ways to raise funds for the provision of health services such as developing risk-sharing mechanisms are often sought [16].

African governments' budgets are insufficient to address health issues, with the growth of health care costs at an alarming rate in many countries [17]. In sub-Saharan Africa, out-of-pocket expenditures constitute approximately $40 \%$ of total health expenditures, imposing financial burdens and limiting access to care in some of the poorest countries around the globe [18].

Developed countries use SHI to mobilize funds and pool risks. But, low and middle-income countries rarely use this approach and rely mostly on general revenues and direct out-of-pocket payments as sources of health care financing[19]. Nevertheless, escalating health care costs, inadequate tax revenues and unsustainable donor funding have alerted governments of developing countries towards the fact that their health sectors need money from sources other than conventional financing sources [20].

Health financing has been a major challenge for Ethiopia. In Ethiopia, the coverage with formal health insurance is very minimal, representing only $0.02-0.03 \%$ of the total population between 1997 and 1998[8]. Similarly as of 2008 , only $1.1 \%$ of Ethiopians had any kind of insurance and the government spends $1 \%$ of its health expenditure on insurance activities [21].

In Ethiopia, the first formal and legal government-based SHI system was established in the year 2010 under legislation passed by Council of Ministers proclamation number 191/2010. The established Ethiopian Health Insurance Agency has been working as an autonomous federal organ, having its legal personality since its establishment. The objective of the Agency is to implement a form of managed care health insurance system in the country. The SHI Implementation Regulation was endorsed by the Council of Ministers. Deployment of employees for the Ethiopian Health Insurance Agency and its regional branch offices is underway $[11,22]$. Even though some studies have been done to address this area of concern; to improve health service utilization in Ethiopia. Even though health insurance is a critical issue where 
concern should be given, there are limited studies on social health insurance and on its willingness to pay and join among civil servants.

This study provides rigorous analysis of the willingness to join and pay the newly proposed social health insurance, and the result will inform evidence-based policy and recommendations to plan for better achievement of the proposed scheme. The finding of the study will give baseline information for the scheme. The recommendation from the survey will also be utilized or helpful for local health planners, health administration, and those organizations working on the health service coverage scale-and finally the finding of the study is a good baseline and can be used by organizations like Ethiopian FMOH, EHIA and any concerning body for the proposed scheme to engage in the implementation phase for better achievements because the program is the best solution for improving health care utilization.

\section{Methods And Materials}

\subsection{Study design, period andarea}

The institutional-based cross-sectional study design was conducted from April 18-30, 2018. The study was conducted in Didu District which is located in southwest Ethiopia, Oromia regional state llubabor zone. The District is one of the 14 Districts in the zone and is located 59 Kilometer from Mettu; the Zone capital. According to Didu District administrative office; the total population of the district was 43,289 , of which the highest percentages of the populations are farmers. The district has 2 health centers and 17 health posts, serving 16 rural kebeles and one urban kebele. According to the data from the district Public service office; there are 890 public sectors workers of different professionals working in 27 public sectors. The District has weather conditions of Dega; the most growing plant is Coffee plant which is the base for economy of the District's population.

\subsection{Population}

\subsubsection{Source population}

- All public sectors workers in the Didu District were considered as the source population.

\subsubsection{Study population}

- Sampled public sectors workers who fulfill the inclusion criteria were considered as the study population.

\subsection{Sample size and samplingprocedure 2.3.1. Sample sizedetermination}

Sample size was calculated by using single population proportion formula:- 
- $n=(z a / 2)^{2} p(1-p) / d^{2}$

- $\mathbf{n}=$ minimal sample size needed.

- $\mathbf{d}=$ desired level of precision.

- $\mathrm{P}=$ proportion (by using $50 \%$ because there is no study done in the country on the topic).

Based on the above assumptions; the calculated sample size was 384 , adding a non-response rate of $10 \%$; the sample size was 420 . Since the total population of the target population is 890 which is less than 10,000; the finite population correction formula must be applied so the final sample size was 285 .

\subsubsection{Samplingprocedure}

Didu District was purposively selected and total number of public sectors workers of the District was taken from Public service office of Didu district. After sample size was determined; all public sectors were included and the sample size was proportionally allocated for all sectors. Finally, a random sampling procedure was used to select a participant from each sector in the District.

\subsection{Study variables}

\subsubsection{Dependent variable}

- Willingness to join social health insurance

\subsubsection{Independent variable}

- Sociodemographic variables[age, sex, marital status, job description, educational status of respondent, religion, ethnicity, monthly income, husband's or wife's occupation, husband's or wife's educational status].

- Health status and health care utilization variables [having a chronic illness, illness episode, illness, illness history, illness recurrence, the seriousness of last illness, where treated illness, paymentrelated problems].

- Social health insurance variables[awareness of social health insurance, knowledge about benefit of social health insurance, the reason for not willing to join, willingness to pay reason for unwilling to pay].

\subsection{Data collection tools andprocedures 2.5.1. Data collection tool}

Interview-administered questionnaires were developed in English addressing sociodemographic, health status, health care utilization information, and social health insurance information including willingness to join and pay social health insurance by reviewing literature and adapting [23-26].

\subsubsection{Data collectionprocedure}


Four diploma holder teachers and two-degree holders' health professionals were recruited and trained as data collectors and supervisors respectively. The English version of the questionnaire was introduced to data collectors and supervisors through a two-day training, and a pre-test was conducted in the Alle District. The training was included objectives of the study, data collection tools, and how the data were collected.

\subsection{Inclusion and Exclusioncriteria 2.6.1. Inclusion criteria}

- All public sector workers who were working in the district at the time of the data collection were included.

\subsubsection{Exclusion Criteria}

- Workers who are seriously ill and can't be availed during the study period.

- Workers who were on their annual break.

- Contract workers.

\subsection{Operational definition}

- Willingness to join:- respondents who answer 'yes' to the questions asking about willingness to join the Social health insurance after explaining the scenario of SHI

- Willingness to pay:-respondents who answer 'yes' to the questions asking about willingness to pay for the social health insurance after explaining the scenario of SHI who are willing to join the scheme.

\subsection{Data processing and analysis}

All the questionnaires will be checked visually, coded, and entered into Epidata version 3.5 and exported to SPSS version 22 software package for analysis. The data were analyzed using binary logistic regression to determine the relationship between factors and the outcome variable. Binary logistic regression was computed to calculate Crude Odds Ratio(COR) with its $95 \%$ confidence interval to test the associations between dependent and independent variables, then variables found to have $P<0.25$ in the bi-variable analysis were taken as candidates for multivariable analysis. Finally, multivariable analysis with Adjusted Odds Ratio (AOR) was computed to control for possible confounders and to identify factors significantly associated with willingness to join social health insurance. The fitness of the model was tested by the Hosmer-Lemeshow goodness of fit test. P-value of $<0.05$ was considered as the criterion for statistical significance. The results were presented in the form of tables, figures, and text using frequencies and summary statistics such as mean, standard deviation, and percentage to describe the study population about relevant variables. 


\subsection{Data Quality control}

The quality of data was assured by proper designing and pre-testing of the questionnaires in one of the districts other than the selected district on $5 \%$ of participants, and by giving training for the data collectors and supervisors before the actual data collection. Every day after data collection, questionnaires were reviewed and checked for completeness and relevance by the supervisors and principal investigators, and then the necessary feedback was offered to data collectors the next morning.

\subsection{Ethical clearance}

Ethical clearance was obtained from the ethical committee of the department of post-graduate studies, Faculty of Public health and Medical science at Mettu University. The respondents were informed about the objective, the purpose, scope, and expected outcome of the research of the study, and verbal consent was obtained from each respondent. Confidentiality of the data was kept by omitting the respondent's name from the questionnaire.

\section{Results}

\subsection{Socio-demographic characteristics}

A total of 280 sampled individuals are interviewed, making a $98.2 \%$ response rate. Among the total respondents, $196(70 \%)$ are males and $84(30 \%)$ are females. The mean age of the respondents was 29.29 years with a standard deviation of \pm 5.36 , and containing a minimum of 19 years and a maximum of 54 years. About the religion of the respondents, 38.2\%, 32.9\%, and $27.9 \%$ were Protestant, Orthodox, and Muslim respectively. The majority of the respondents are married, $182(65 \%)$. Out of 280 respondents, 265(94.6) are Oromo in ethnicity. Regarding the job description of respondents, $72.1 \%$ are technical workers. Out of all respondents, $46 \%$ had education status of degree and above and about $44 \%$ had diploma level [Table 1]. 
Table 1

Sociodemographic characteristic of the study participants, Didu District, Oromia region, Southwestern Ethiopia, $2018(n=280)$.

\begin{tabular}{|c|c|c|}
\hline Variables & Category & Frequency $(n, \%)$ \\
\hline \multirow[t]{2}{*}{ Sex } & Male & $196(70)$ \\
\hline & Female & $84(30)$ \\
\hline \multirow[t]{4}{*}{ Marital status } & Married & $182(65)$ \\
\hline & Single & $86(30.7)$ \\
\hline & Divorced & $10(3.6)$ \\
\hline & Widowed & $2(0.7)$ \\
\hline \multirow[t]{4}{*}{ Religion } & Muslim & $78(27.9)$ \\
\hline & Orthodox & $92(32.9)$ \\
\hline & Protestant & $107(38.2)$ \\
\hline & Others & $3(1.1)$ \\
\hline \multirow[t]{4}{*}{ Ethnicity } & Oromo & $265(94.6)$ \\
\hline & Amhara & $6(2.1)$ \\
\hline & Kaffa & $3(1.1)$ \\
\hline & Others & $6(2.1)$ \\
\hline \multirow[t]{3}{*}{ Job description } & Managerial & $34(12.1)$ \\
\hline & Technical workers & $202(72.2)$ \\
\hline & Supportive workers & $44(15.7)$ \\
\hline \multirow[t]{4}{*}{ Educational status } & Grade 10 or 12 completed & $12(6.1)$ \\
\hline & Certificate & $10(3.6)$ \\
\hline & Diploma & $129(46.1)$ \\
\hline & Degree and above & $124(44.3)$ \\
\hline \multirow[t]{4}{*}{ Husband's/wife's Educational status } & Grade 10 or 12 completed & $51(25.9)$ \\
\hline & Certificate & $11(5.6)$ \\
\hline & Diploma & $79(40.1)$ \\
\hline & Degree and above & $56(28.4)$ \\
\hline
\end{tabular}




\begin{tabular}{|lll|}
\hline Variables & Category & Frequency (n, \%) \\
\hline Husband's/wife's occupation & Farmer & $14(7.1)$ \\
& Gov't employee & $144(73.1)$ \\
& Merchant & $22(11.2)$ \\
& Daily labourer & $3(1.5)$ \\
& Others & $14(7.1)$ \\
\hline
\end{tabular}

\subsection{Health status and health care utilization}

About one-fourth of 65 (23.4\%) of the respondents responded that members of their family have a chronic illness, and the remaining $213(76.6 \%)$ have no type of chronic illness from their family member. One hundred eighty-one (65.1\%) of the individuals had at least one episode of illness within the last 12 months, and the remaining $34.9 \%$ had no of any illness in the last 12 months. Concerning the question asking what is the latest episode you have encountered illness; about $26.9 \%$ of the respondents answered they have phased $1-3$ months and $6-12$ months, $23.7 \%$ of them $3-6$ months and $13.7 \%$ within one month before data collection with illness episode of those diseased ranges from 1-7 times with mean of 2.09 and 1.22 standard deviation. Those who had episodes of disease and were asked to be treated in the last episode answered public facility, private facility, did nothing, traditional healer $56.1 \%, 36.5 \%, 6.3 \%$, and $0.5 \%$ respectively.

Regarding whom cover health care cost during illness time; the Majority of them 185 (97.9\%) said they cover their health care cost on their own(self) when only less than $2 \%$ have other means of coverage like government. Concerning the amount paid for health, the cost ranges from 20-2850 Ethiopian Birr (ETB) with a mean of $\mathbf{4 6 5}$ and a standard deviation of 622.65 . For the question asking about how they think about the problem of paying for health care: $-36.2 \%, 33.8 \%$, and $30 \%$ answered very difficult, difficult, and not difficult respectively. About $74.6 \%, 195,2.4 \%$, and $3.9 \%$ of the individuals had made payment for medical care out of pocket, borrowed money, government fee, and others respectively. Regarding satisfaction with health care service; about $36.7 \%$ of them responded that they are dissatisfied, $19.1 \%$ very dissatisfied, $7.4 \%$ neutral, $30.1 \%$ satisfied, and very satisfied with the service they got. Out of 245 respondents, 74(30.2\%) had borrowed money, and 171(69.8\%) had not borrowed money for medical care.

\subsection{Social health insurance}

Among 280 individuals asked about whether they have ever heard about SHI; about 186 (66.4\%) had heard, but the remaining 94(33.6) have not ever heard about social health insurance. Sources of information were Television 83(44.4\%), Health facility 48(25.7\%), Radio 32(17.1\%), and Coworkers $21(11.2 \%)$ among individuals who have heard about SHI. Regarding willingness to join, SHI; about $133(47.5 \%)$ are willing to join, and the rest were not willing to join it. Of the individuals who are willing to join; $78(58.6 \%)$ were willing to pay, and the rest were not. Of those not willing to pay; about $41.8 \%, 30.9 \%$, $12.1 \%, 10.9 \%$, and $3.6 \%$ answered that it's the government's responsibility, the project is not clear, the 
percent is high, out of pocket better and other reasons respectively. The reason for being unwilling to join SHI as expressed by the respondents were:-doesn't cover all services (57\%), don't include all family members (28\%), poor implementation (26\%), and always good health (10\%).

\subsection{Bivariate logistic regression 3.4.1. Willingness to join SHI}

In bivariate logistic regression; factors associated with willingness to join SHI were: Age of the respondent, marital status, job description, monthly salary, family size, where they have been treated, why they have been treated there, how much they paid, how you pay a service fee, what is your satisfaction for medical service and the previous history of borrowing money for service fee in past had a relationship with willingness to join and pay SHI at P-value $<0.25$. These variables were selected as a candidate for multivariable logistic regression for further analysis.

Respondents who are on the technical job description are 3 times more likely to be willing to join SHI than supportive workers (COR: $2.89,95 \% \mathrm{Cl}: 1.4,5.9$ ). Workers who get a monthly salary of 1500-2999 ETB were 2 times more likely to be willing to join SHI than those who get monthly salary greater than 4500 ETB (COR: 2.253, 95\% Cl:1.219,4.167)[Table 2]. 
Table 2

A Bivariate logistic regression analysis output for factors associated with willingness to join $\mathrm{SHI}$ among public sector workers in Didu district, Southwestern Ethiopia,2018 $(n=280)$.

\begin{tabular}{|c|c|c|c|c|c|}
\hline \multirow[t]{3}{*}{ Variables } & \multirow[t]{3}{*}{ Categories } & \multicolumn{2}{|c|}{ Willingness to join SHI } & \multirow[t]{3}{*}{$\operatorname{COR}(95 \% \mathrm{Cl})$} & \multirow{3}{*}{$\begin{array}{l}\mathrm{P}- \\
\text { value }\end{array}$} \\
\hline & & Yes & No & & \\
\hline & & $\mathbf{N}(\%)$ & $\mathbf{N}(\%)$ & & \\
\hline \multirow[t]{4}{*}{ Age( years) } & $20-21$ & 104(57.7) & $76(42.3)$ & 1 & 0.00 \\
\hline & $30-39$ & $26(28.5)$ & $65(71.5)$ & $0.292(0.17,0.503)^{\star}$ & \multirow[t]{3}{*}{0.706} \\
\hline & $40-49$ & $3(50)$ & $3(50)$ & $0.731(0.144,3.72)$ & \\
\hline & $\geq 50$ & $0(0)$ & $3(100)$ & 0 & \\
\hline \multirow[t]{4}{*}{ Marital status } & Married & $75(41.2)$ & $107(58.8)$ & $0.5(0.3,0.849) \star$ & 0.010 \\
\hline & Divorced & $7(70)$ & $3(30)$ & $1.68(0.4,6.9)$ & 0.474 \\
\hline & Widowed & $1(50)$ & $1(50)$ & $0.72(.044-11.89)$ & \multirow[t]{2}{*}{0.818} \\
\hline & Single & $50(58.1)$ & $36(41.9)$ & 1 & \\
\hline \multirow[t]{3}{*}{ Job description } & Managerial & $34(12)$ & $246(88)$ & $2.37(0.92,6.1)$ & 0.074 \\
\hline & $\begin{array}{l}\text { Technical } \\
\text { workers }\end{array}$ & 202(72) & $78(28)$ & $2.887(1.4,5.9)^{\star}$ & \multirow[t]{2}{*}{0.004} \\
\hline & $\begin{array}{l}\text { Supportive } \\
\text { workers }\end{array}$ & $44(15.7)$ & $236(84.3)$ & 1 & \\
\hline \multirow[t]{4}{*}{ Monthly salary } & $<1500$ & 13(92.8) & $1(1.2)$ & \multirow{4}{*}{$\begin{array}{l}0.137(0.017,1.106) \\
2.253(1.219,4.167) \star \\
1.835(0.957,3.52) \\
1\end{array}$} & 0.062 \\
\hline & $1500-2999$ & $53(55.8)$ & $42(44.2)$ & & 0.010 \\
\hline & $3000-4500$ & $37(50.6)$ & $36(49.4)$ & & 0.068 \\
\hline & $>4500$ & 28(35.9) & $50(64.1)$ & & \\
\hline \multirow[t]{3}{*}{ Family size } & $1-2$ & $73(54.5)$ & $61(45.5)$ & $3.83(1.743,8.415)^{\star}$ & 0.001 \\
\hline & $3-4$ & $50(48.6)$ & $53(51.4$ & $3.019(1.345,6.775)^{\star}$ & \multirow[t]{2}{*}{0.007} \\
\hline & $>4$ & 10(23.8) & $32(72.2)$ & 1 & \\
\hline \multirow[t]{4}{*}{ Why you go there } & Self-limiting & $3(23)$ & $10(77)$ & $0.05(0.004,0.597)^{\star}$ & 0.05 \\
\hline & Accessible & $50(60.2)$ & $33(39.8)$ & $0.253(0.029,2.14)$ & 0.253 \\
\hline & Not expensive & $36(41.4)$ & $51(59.6)$ & $0.118(.014,1.02)$ & \multirow[t]{2}{*}{0.118} \\
\hline & Others & $6(85.7)$ & $1(14.3)$ & 1 & \\
\hline \multirow{2}{*}{$\begin{array}{l}\text { How much you } \\
\text { pay(ETB) }\end{array}$} & $<1000$ & $77(56.2$ & $60(45.8)$ & $4.1(1.424,11.846)^{\star}$ & \multirow[t]{2}{*}{0.009} \\
\hline & $\geq 1000$ & $5(23.8)$ & 16(76.2) & 1 & \\
\hline
\end{tabular}




\begin{tabular}{|c|c|c|c|c|c|}
\hline \multirow[t]{3}{*}{ Variables } & \multirow[t]{3}{*}{ Categories } & \multicolumn{2}{|c|}{ Willingness to join SHI } & \multirow[t]{3}{*}{$\operatorname{COR}(95 \% \mathrm{Cl})$} & \multirow{3}{*}{$\begin{array}{l}\mathrm{P} \text { - } \\
\text { value }\end{array}$} \\
\hline & & Yes & No & & \\
\hline & & $N(\%)$ & $N(\%)$ & & \\
\hline \multirow{5}{*}{$\begin{array}{l}\text { How you satisfied } \\
\text { with care }\end{array}$} & \multirow{2}{*}{$\begin{array}{l}\text { Very } \\
\text { dissatisfied }\end{array}$} & $32(65.3)$ & $17(34.7)$ & $1.73(.546,5.125)$ & 0.367 \\
\hline & & $26(30.2)$ & $60(69.8)$ & $0.34(.118, .975)^{\star}$ & 0.045 \\
\hline & Dissatisfied & $12(63.1)$ & $7(36.9)$ & $1.524(.402,5.777)$ & 0.536 \\
\hline & \multirow{2}{*}{$\begin{array}{l}\text { Satisfied } \\
\text { Very satisfied }\end{array}$} & $47(61)$ & $30(39)$ & $1.393(.484,4.007)$ & 0.539 \\
\hline & & $9(52.9)$ & $8(47.1)$ & 1 & \\
\hline \multirow[t]{2}{*}{ Borrow money } & Yes & $41(33.6)$ & $81(66.4)$ & $.724(.419,1.253)$ & 0.249 \\
\hline & No & $33(26.8)$ & $90(73.2)$ & 1 & \\
\hline
\end{tabular}

\section{Note: - * Significant at p-value 0.05 .}

\subsection{Multivariable logistic regression for Willingness to join}

In multivariate logistic regression, factors associated with willingness to join SHI were: - Age of the respondent, marital status, job description, how much you pay, and what is your satisfaction for medical care had a relationship with willingness to join Social health insurance in multivariate logistic regression.

This study revealed that individuals' age was significantly associated and individuals falling in the age range of 30-39 years were less likely to join SHI as compared to those $20-29$ years(AOR:0.212, 95\% Cl: $0.07,0.642$ ). The study showed that the job description of the respondents was significantly associated, and supportive staffs were less likely to join $\mathrm{SHI}$ as compared to those in managerial positions (AOR:0.016, 95\% Cl: 0.002,0.144). How much you pay was significantly associated, those paid $<1000$ ETB were 6-fold more likely than those paid > 1000 ETB (AOR: 5.932, 95\% Cl: 1.708, 32.631). Satisfaction of respondents was significantly associated, those that were dissatisfied was less likely associated to join SHI (AOR: $0.053,95 \% \mathrm{Cl}: 0.013,0.223)$, and also those that had a previous history of borrowing money was negatively associated with a willingness to join (AOR: $0.312,95 \% \mathrm{Cl}: 0.115,0.848$ ) [Table 3$]$. 
Table 3

Multivariable logistic regression output for factors associated with willingness to join SHI among public sector workers in Didu district, Southwestern Ethiopia, 2018( $\mathrm{n}=280)$.

\begin{tabular}{|c|c|c|c|c|c|}
\hline \multirow[t]{3}{*}{ Variables } & \multirow[t]{3}{*}{ Categories } & \multicolumn{2}{|l|}{ WTJ } & \multirow[t]{3}{*}{$\operatorname{coR}(95 \% \mathrm{Cl})$} & \multirow[t]{3}{*}{ AOR(95\% Cl) } \\
\hline & & Yes & No & & \\
\hline & & No (\%) & No (\%) & & \\
\hline \multirow[t]{3}{*}{ Age(years) } & $20-29$ & 104(57.7) & $76(42.3)$ & 1 & 1 \\
\hline & $30-39$ & $26(28.5)$ & $65(71.5)$ & $0.292(0.17,0.503)^{\star}$ & $.212(.07, .642)^{\star}$ \\
\hline & $\geq 40$ & $3(50)$ & $3(50)$ & $0.731(0.144,3.72)$ & $.365(.089,1.5)$ \\
\hline \multirow[t]{2}{*}{ Marital status } & $\begin{array}{l}\text { Married } \\
\text { before }\end{array}$ & $83(41.2)$ & $111(58.8)$ & $0.5(0.3,0.849)$ * & $5.59(1.26,24.8)^{\star}$ \\
\hline & $\begin{array}{l}\text { Never } \\
\text { married }\end{array}$ & $50(58.1)$ & $36(41.9)$ & 1 & 1 \\
\hline \multirow{3}{*}{$\begin{array}{l}\text { Job } \\
\text { description }\end{array}$} & Managerial & $34(12)$ & $246(88)$ & $2.37(0.92,6.1)$ & 1 \\
\hline & $\begin{array}{l}\text { Technical } \\
\text { workers }\end{array}$ & $202(72)$ & $78(28)$ & $2.887(1.4,5.9)^{*}$ & $.373(.09,1.553)$ \\
\hline & $\begin{array}{l}\text { Supportive } \\
\text { workers }\end{array}$ & $44(15.7)$ & $236(84.3)$ & 1 & $.016(.002, .141)^{\star}$ \\
\hline \multirow{2}{*}{$\begin{array}{l}\text { How much } \\
\text { you pay(ETB) }\end{array}$} & $<1000$ & $77(56.2$ & $60(45.8)$ & $4.1(1.424,11.846)^{*}$ & $5.93(1.078,32.63) *$ \\
\hline & $\geq 1000$ & $5(23.8)$ & 16(76.2) & 1 & \\
\hline \multirow{5}{*}{$\begin{array}{l}\text { How you } \\
\text { satisfied with } \\
\text { care }\end{array}$} & \multirow{2}{*}{$\begin{array}{l}\text { Very } \\
\text { dissatisfied }\end{array}$} & $32(65.3)$ & $17(34.7)$ & $1.73(.546,5.125)$ & 1 \\
\hline & & $26(30.2)$ & $60(69.8)$ & $0.34(.118, .975)^{\star}$ & $.053(.013, .223)^{\star}$ \\
\hline & Dissatisfied & $12(63.1)$ & $7(36.9)$ & $1.524(.402,5.777)$ & $.220(.32,1.499)$ \\
\hline & Satisfied & $47(61)$ & $30(39)$ & $1.393(.484,4.007)$ & $.484(.12,1.956)$ \\
\hline & $\begin{array}{l}\text { Very } \\
\text { satisfied }\end{array}$ & $9(52.9)$ & $8(47.1)$ & 1 & $.274(.033,2.262)$ \\
\hline \multirow[t]{2}{*}{ Borrow money } & Yes & $41(33.6)$ & $81(66.4)$ & $.724(.419,1.253)$ & $.312(.115, .848)^{\star}$ \\
\hline & No & $33(26.8)$ & $90(73.2)$ & 1 & 1 \\
\hline
\end{tabular}

Note: - * significant at P-value 0.05 .

\section{Discussion}

This study finding showed that $36.5 \%$ of the respondents have not heard about SHI in the past. About $47.5 \%$ were willing to join $\mathrm{SHI}$, out of those who were willing to join more than half (58.6\%) were willing to 
pay the proposed $3 \%$ of their salary monthly. This finding was lower than compared to a study done in Wolaita, Ethiopia in 2012 among teachers in which $71.3 \%$ of them were willing to join and $74.4 \%$ were willing to pay among those who were willing to join [26]. This discrepancy may be due to the socioeconomic and educational status of the study population; teachers might be more educated and have better access to know about the subject, whereas that of this study area is less to get full information. Likewise, a study done in Uganda Kampala on employee's enrollment in SHI showed a willingness to join was $77 \%$ and willingness to pay was $91 \%$. Another study done in Addis Ababa on formal employee preference of health insurance showed $90.2 \%$ were willing to pay for health insurance $[23,24]$. This is again better than this study; this may be due to the difference in socio-economic, sociocultural, and political commitment toward the scheme.

This study finding is better than the study done in Addis Ababa on willingness to pay SHI among health professionals which showed only $17 \%$ of respondents are willing to pay for the insurance[25], study done in Uganda in 2009 showed a willingness to pay for SHI among employee showed a willingness to pay was less than $50 \%[27]$. This difference may be attributed to the socio-cultural, socio-economic, educational, and political commitment of the countries toward the program.

In terms of method of payment for medical service when ill (bill), it was found to be $74.6 \%$ was out of pocket, which was almost in line with the study conducted in Wolaita, Ethiopia [26]. When we look at awareness about SHI; $33 \%$ of the respondents in the study have not heard of SHI, and it was almost in line with a study done in Wolaita, and in Addis Ababa, Ethiopia $[26,28]$. This may be the implication of low respondent willingness to join $\mathrm{SHI}$.

This study finding showed that the age of an individual was significantly associated with a willingness to join SHI. It was in line with the study done in Ethiopia, which showed elders were less likely to participate in insurance [23]. This may be due to the low adaptation of elders to new technology as compared to the young.

The study also revealed that marital status was significantly associated with a willingness to join SHI. The married individual was 6 times more willing to join when compared to the unmarried one. This may be due to an increase in family size and the inclusiveness of family members. Job description of the respondents was significantly associated with a willingness to join $\mathrm{SHI}$, in which supportive staffs were less likely to be willing to join SHI.

The amount of birr paid was significantly associated with a willingness to join $\mathrm{SHI}$, those who have paid less than 1000 ETB were 6 folds more likely to be willing to join SHI. Also, the satisfaction of respondents to health care was significantly associated with willingness to join; the dissatisfied were less likely to participate as compared to those very satisfied. This may be the reason for the quality and health care providers of the public facilities in terms of the service fee and supply.

\section{Conclusion And Recommendation}




\subsection{Conclusion}

Willingness to join and pay SHI was found to be low in the study area. Age of the respondents, marital status, job description, how much you paid?, satisfaction of the respondents for the service, and history of borrowing money for service fee were significantly associated with willingness to join SHI.

\subsection{Recommendation}

For Federal ministry of health and Ethiopian health insurance agency:-

- Almost half of the government employees were willing to join the SHI scheme and implementation would be easier if potential enrols know how it works and benefits would be because from those willing to join the two-thirds were willing to contribute the proposed $3 \%$ from their monthly salary.

- Should disseminate information to create awareness on SHI (Initiatives to overcome this lack of awareness, awareness campaigns, mass media, and sensitization by scheme staff) to promote the starting of the scheme.

- Health policymakers should engage key stakeholders and prepare for workshops and training for the program.

- Should make health facility qualified and satisfactory to give service adequately.

\section{For researchers and scholars:-}

- Interested researchers are recommended to upgrade the study to a more broad geographical area to make sound research.

\section{Abbreviations}

- EHIA:-Ethiopia Health Insurance Agency

- ETB:- Ethiopian Birr

- FMOH:- Federal Ministry of Health

- HSFR:- Health Sector Financing Reform

- SHI:-Social Health Insurance

- WHO:-World Health Organization

- WTJ:-Willingness To Join

- WTP:-Willingness To Pay

\section{Declarations}

\section{Acknowledgements}


We are grateful to academicians and experts from Mettu University Department of Public Health and post-graduate studies for their valuable contribution during the study. Our special thanks also go to the Didu District health office, study participants, and different sector workers for facilitating the process of data collection. And we would like to thank the data collectors and supervisors for their contribution to data collection and coordination activities.

\section{Ethics approval and consent to participate}

Ethical clearance was obtained from the ethical committee of the department of post-graduate studies, Faculty of Public health and Medical science at Mettu University. A formal letter was taken from IluAbabora Zonal Health Office to all concerned sectors of the study area. The respondents were informed about the objective, the purpose, scope, and expected outcome of the research of the study, and verbal consent was obtained from each respondent. Confidentiality of the data was kept by omitting the respondent's name from the questionnaire.

\section{Consent for publication}

'Not applicable'

\section{Availability of data and materials}

The finding of this study was generated from the data collected and analyzed based on stated methods and materials. The original data supporting this finding are available from the corresponding author on reasonable request.

\section{Competing interests}

"The authors declare that they have no competing interests"

\section{Funding}

'Not applicable'

\section{Authors' contributions}

ZR participated in the design of the study, performed the data collection and statistical analysis, and served as the corresponding author of the manuscript. EN, TS, and ZK supervised the study, ensured the 
quality of the data, assisted in the analysis and interpretation of the data. All authors read and approved the manuscript.

\section{References}

1. World Health Organization. Constitution of the World Health Organization. Geneva, Switzerland; 2006.

2. The World Health Report: Research for Universal Health Coverage; 2013.

3. The World Health Report. Health Systems Financing: the Path to Universal Coverage. World Health Organization, Geneva, Switzerland; 2010

4. World Health Organization. Resolution WHA58.33. Sustainable Health Financing, Universal Coverage, and Social Health Insurance. Fifty-eighth World Health Assembly, Resolutions and Decisions. Geneva, Switzerland; Volume 1. 16-25 May 2005.

5. United Nation. United Nations General Assembly Resolution A/RES/67/81. Global Health and Foreign Policy. Sixty-Seventh Sessions Agenda item 123; 2012.

6. Evans DB, Marten R, Etienne C. Universal Health Coverage is a Development Issue. Lancet; 2012.

7. Till B, Arnighausen N, Rainer S. One Hundred and Eighteen Years of the German Health Insurance System: Are there Any Lessons for Middle- and Low-Income Countries? Elsevier Science Ltd. University of Heidelberg. Heidelberg, Germany; 2002.

8. Andrew F, Piya HA, Matthew J, Diana P, Sreekanth Ra, Paul Sh. Co-author. William C. Hsiao, In collaboration with The World Bank. Social Health Insurancefor Developing Nations. Harvard University School of Public Health, USA: January 2006.

9. Guy C. World Health Organization. Social Health Insurance in Developing Countries: A Continuing Challenge. Volume 55. International Social Security Review; 2002.

10. Social Health Insurance for Developing Nations: William C. Hsiao Harvard University School of Public Health and R. Paul Shaw World Bank Institute, 2007.

11. Registration number -191-2010. Article 10 of the Social Health Insurance and Proclamation No. 690/2010: The Ethiopian Health insurance Agency. Addis Ababa, Ethiopia; 2010.

12. Social Health Insurance. Key factors Affecting the Transition Towards Universal Health Coverage, International Social Security Association. International Social Security Review, Vol. 58, 1/2005, WHO, Geneva, Switzerland; 2005.

13. Health Insurance in Low-Income Countries: Joint NGO Briefing Paper, Oxfam International; May 2008.

14. Mehrotra A, Adams JL, Armstrong K, Eibner C, Hussey PS, Lave J, Liu H, McGlynn EA, Pollack CE, Ridgely MS, Rudavsky R. Health care on aisle 7: The growing phenomenon of retail clinics. Santa Monica, Calif.: RAND Corporation, RB-9491-1. 2010.

15. INFORM Unit. Information for Health Management: the MSH approach: Management Science for Health. Boston MA. USA; 2005. 
16. Asgary A, Willis K, Taghvaei A.A, and Rafeian Estimating rural household's willingness to pay for health insurance. Eur J Health Economy 2004; 5:209-215.

17. The State of Healthcare in Africa (https://www.kpmgafrica.com/state-healthcare-in-africareport/). Available from; December 7, 2012.

18. Mbengue, Cheikh. Revitalizing Community-based Health Insurance in Africa toward Universal Coverage. Health Systems 20/20 Project. Abt Associates Inc. February 28, 2011.

19. Hsiao W.C and Shaw R.P. Social health insurance for developing nations. Washington: the international bank for reconstruction and development. The World Bank, 2007; 31-4.

20. Mclntyre D, lucy G, and Vimbayi M. Promoting equitable health care financing in the African context: Current challenges and prospects. Global Forum for Health Research, 2007; 45-8.Federal Ministry of Health Planning and Programming Department. Health Insurance Strategy. Addis Ababa 2008; 13-7.

21. (FMOH) Ethiopia Federal Ministry of Health. April 2014. Ethiopia's Fifth National Health Accounts, 2010/2011. Addis Ababa, Ethiopia.

22. Preference for health care financing options and willingness to pay for compulsory health insurance among government employees in Ethiopia: Umeålnternational School of Public Health, Umeå University, Sweden, 2009.

23. Muheki CW. Willingness to pay for social health insurance: a case study of Kampala (Uganda). University of Cape Town; 1998.

24. YaredLasebew,YeshwondmMamuye, SemiraAbdelmenan. Willingness to Pay for the Newly Proposed Social Health Insurance among Health Workers at St. Paul's Hospital Millennium Medical College, Addis Ababa, Ethiopia. International Journal of Health Economics and Policy. Vol. 2, No. 4, 2017, pp. 159-166. DOI: 10.11648/j.hep.20170204.13.

25. Tesfamichael et al: Willingness To Join And Pay For The Newly Proposed Social Health Insurance Among Teachers In WolaitaSodo Town, South Ethiopia, Ethiopian Journal Of Health Science 2014,24(3).

26. Byabashaija AA. The knowledge and views of teachers in government educational institutions in Kampala district on the proposed social health insurance scheme in Uganda. 2009.

27. Obse et al.: knowledge and preference of health insurance among formal sector employees in Addis Ababa.BMC health services research 2015 15:318. DOI 10.1186/s12913-015-0988-8.

\section{Supplementary Files}

This is a list of supplementary files associated with this preprint. Click to download.

- DataCollectionToolsAdditionalFile1.docx 